\title{
Measurement of Waist Circumference at Four Different Sites in Children, Adolescents, and Young Adults: Concordance and Correlation with Nutritional Status as well as Cardiometabolic Risk Factors
}

\author{
Britta Hitze $^{\mathrm{a}}$ Anja Bosy-Westphal ${ }^{\mathrm{a}}$ Fenja Bielfeldt ${ }^{\mathrm{a}}$ Uta Settler ${ }^{\mathrm{a}}$ Heiner Mönig ${ }^{\mathrm{b}}$ \\ Manfred James Müller ${ }^{\mathrm{a}}$ \\ a Institut für Humanernährung und Lebensmittelkunde, Christian-Albrechts Universität Kiel, \\ ${ }^{b}$ Klinik für Allgemeine Innere Medizin, Universitätsklinikum Schleswig-Holstein, Kiel, Germany
}

\section{Key Words}

Waist circumference $\cdot$ Measurement site $\cdot$ Cardiometabolic risk

\section{Summary}

Background: This study investigates the concordance of four waist circumference (WC) measurement sites, and examines their relationships with nutritional status and cardiometabolic risk. Subjects and Methods: In 91 females / 89 males (6.1-19.9 years; $12.2 \%$ overweight), WC was assessed beneath the lowest rib (WCR), $4 \mathrm{~cm}$ above the umbilicus (WC4), above the iliac crest (WCC), and midway between WCR/WCC (WCM). 'Overwaist' was defined as a WC > 90th age-/sex-specific percentile. Pubertal stage was assessed according to Tanner. Body composition (air-displacement plethysmography), blood pressure, lipid profile, glucose/insulin levels, and HOMA-IR (homeostasis model assessment of insulin resistance) were measured. Results: Medians of WCs $(\mathrm{cm})$ for females/males were WCR (64.4/69.5) < WC4 (64.6/70.2) < WCM (67.1/71.2) < WCC (71.5/ 74.2). Although closely related to each other (all $r>0.93$; $p<0.001$ ), paired comparisons revealed differences between WCs in their magnitudes which was stronger for females than males. Prevalence of 'overwaist' differed according to measurement site in females/males: WCR $(13.2 / 15.7 \%)<$ WC4 $(14.3 /$ $19.1 \%)<$ WCM $(18.7 / 22.5 \%)<$ WCC $(37.4 / 30.3 \%)$. After adjusting for age and pubertal status, WCs were closely related to body mass index (BMI) (all $r>0.86 ; p<0.001$ ), percent fat mass (\%FM; all $r>0.61 ; p<0.001)$, and comparably associated with cardiometabolic risk factors. However, stronger correlations were found for i) WCR vs. WC4 with BMI in males ( $r=0.93$ vs. $0.91 ; p<0.05)$, ii) WCC vs. WC4 with \%FM in females ( $r=0.67$ vs. $0.61 ; p<0.05)$, iii) WCC vs. WCR with triglycerides in females $(r=0.29$ vs. $r=0.22 ; p<0.05)$, and iv) WCC $(r=0.36)$ vs. other WCs $(r=0.30-0.32)$ with low-density lipoprotein cholesterol $($ LDL-C) in males $(p<0.05)$. Conclusion: WCs measured at different sites were closely correlated with $\mathrm{BMI}$ and \%FM as well as comparably associated with cardiometabolic risk factors. However, different WCs had different magnitudes, which was more obvious in females and led to discordant results with respect to 'overwaist' and risk assessment.

\section{Introduction}

Childhood overweight has become a major public health concern, and its prevalence is increasing worldwide [1]. Adverse health outcomes include early manifestations of diabetes mellitus, coronary heart disease, hypertension, and hyperlipidaemia [2-5]. Thus, early identification, prevention, and treatment of children at risk are a challenge. There is a need of proxies for childhood overweight and its co-morbidities, which should be simple to assess but sensitive and accurate [6]. Waist circumference (WC) was shown to be a good measure of overweight and its co-morbidities [4, 6-8]. Moreover, WC was described to be a good measure of abdominal obesity and visceral adipose tissue (VAT) [9,10], which are more closely related to cardiovascular risk than overweight as assessed by body mass index (BMI) per se.

However, there is no standardised protocol for measuring WC. Wang et al. [11] found 14 different descriptions for the WC measurement site. However, these sites can be grouped as: i) directly below the lowest rib (WCR), ii) at the narrowest waist (which often is at the lowest rib), iii) midway between the lowest rib and the iliac crest (WCM), and iv) directly above the iliac crest (WCC) [11]. A recent study favoured another measurement site for WC in children, which was $4 \mathrm{~cm}$ above the umbilicus (WC4) [12]. Up to now, few studies have compared implications of measuring $\mathrm{WC}$ at different sites. Wang et al. used four WC measurement sites in 111 subjects aged 7-83 years. They found that these WCs differed in their magnitude, and that the values were more depended on the specific site in females compared to males [11]. Rudolf et al. [12] investigated a small sample of children/adolescents ( $\mathrm{n}=$ 41;31 girls, 11 obese subjects), and showed that three different WC measurement sites were highly correlated with each other

\section{KARGER}

Fax +497614520714

Information@Karger.de

www.karger.com

\section{(c) 2008 S. Karger GmbH, Freiburg}

Accessible online at:

www.karger.com/ofa
Prof. Dr. med. Manfred J. Müller

Institute of Human Nutrition and Food Science

Christian-Albrechts University Kiel

Düsternbrooker Weg 17-19, 24105 Kiel, Germany

Tel. +49 431 88056-70, Fax -79

mmueller@nutrfoodsc.uni-kiel.de 
as well as with BMI. Nevertheless, there was a bias and variability between different measures of WC. In adults, WCR (compared to WCM and WCC) was the only predictor of VAT as assessed by computed tomography in a regression model, although all WCs were closely correlated with VAT. Moreover, a high WCR (compared to WCM and WCC) was associated with a higher glucose concentration; WCR and WCM differentiated normal from elevated triacylglycerol levels [13]. Since the need of an internationally accepted WC measurement site was disclosed $[11,12]$, further research is needed in this field.

This study used data of 91 female and 89 male subjects (6.1-19.9 years; $12.2 \%$ overweight), where $\mathrm{WC}$ was assessed at four different sites (WCR, WC4, WCM, WCC)). The aims of the study were i) to investigate the concordance of $4 \mathrm{WC}$ measurement sites among each other, and to examine their relationships with ii) nutritional status and iii) cardiometabolic risk factors.

\section{Subjects and Methods}

\section{Study Design and Population}

91 female and 89 male subjects $(13.2 \pm 3.7$ years $)$ of Caucasian descent were recruited by notice board postings, writing to families who attended the Kiel Obesity Prevention Study (KOPS) [14], and publicity of participants. Subjects did not take any medication known to influence body composition or cardiometabolic risk factors. The local Ethics Committee of the Christian-Albrechts-University in Kiel (Germany) approved the study. Written informed consent was obtained from each child/adolescent and their legal guardian before measurement, or by the subject itself. The study meets the standards of the Declaration of Helsinki in its revised version of 1975 and its amendments of 1983,1989, and 1996.

\section{Assessment of Nutritional Status and Pubertal Stage}

After an overnight fast, height was measured to the nearest $0.5 \mathrm{~cm}$ against a stadiometer (SECA, Modell 220, SECA, Hamburg, Germany). Body weight was measured to the nearest gram using the digital scale coupled to the BodPod ${ }^{\mathrm{TM}}$ system (Body Compostion System, Life Measurement Instruments, Concord, CA, USA). BMI was calculated as weight (kg)/ height $\left(\mathrm{m}^{2}\right)$. German reference percentiles were used to calculate BMISDS (standard deviation score) and to define overweight (>90th percentile) [15]. The upper age limit of 18.5 years for these references resulted in 171 children/adolescents for this analysis. For adults, WHO references were used to define overweight [16].

Subjects were dressed in underwear, and WC was measured at 4 different sites to the nearest $0.5 \mathrm{~cm}$ at minimal respiration. An inelastic tape was placed directly on the skin, while subjects stood balanced on both feet with their arms hanging freely. Four WCs were measured by a single observer: i) directly beneath the lowest rib (WCR), ii) $4 \mathrm{~cm}$ above the umbilicus (WC4), iii) midway between the lowest rib and the iliac crest (WCM), and iv) directly above the iliac crest (WCC). The intra-observer coefficients of variation (CVs) of 4 trained observers were $0.6 \%$ (WCR), $1.5 \%$ (WC4), $1.1 \%$ (WCM), and $0.7 \%$ (WCC). The corresponding interobserver CVs were $1.0 \%$ (WCR), $1.1 \%$ (WC4), $1.9 \%$ (WCM), and $3.1 \%$ (WCC).

'Overwaist' was defined as a WC exceeding 90th age-/sex-specific percentile of Dutch reference values [17] which were generated from WC measurements midway between the lowest rib and the iliac crest in 14,500 children, adolescents, and young adults (age range: 0-21 years). Vice versa, 'normal waist' was defined as a WC $\leq 90$ th percentile. Hip circumference was measured at the level of symphysis, and waist-to-hip ratios were calculated. Body composition (fat mass (FM) and fat-free mass (FFM)) was assessed by air-displacement plethysmography (ADP; BodPod ${ }^{\mathrm{TM}}$, Life Measurement Instruments), and child-specific corrections for ADP were applied as described elsewhere [18]. Tanner stages of pubertal development (pubic hair stages for both sexes, breast stage for females, and genitalia stages for males) were assessed by using standard pictures on scales from 1 to 5 according to Tanner [19]. For children aged younger than 10 years, Tanner stage 1 was chosen. Children and adolescents older than 10 years reported their pubertal stage by themselves. This procedure has been validated by Duke et al. [20].

\section{Cardiometabolic Risk Factors}

Blood pressure was measured with a standard manual sphygmomanometer in a seated position. Glucose levels and lipid profile were measured in series on a VITROS ${ }^{\circledR} 950$ Chemistry System autoanalyser (ortho-Clinical Diagnostics, Neckargemünd, Germany), low-density lipoprotein cholesterol (LDL-C) was calculated using the Friedewald equation [21]. Radioimmunoassay was used to assess plasma insulin levels (Adaltis, Freiburg i.Br., Germany; $\mathrm{CV}<5.4 \%$ ), and insulin resistance was calculated by homeostasis model assessment of insulin resistance: HOMA-IR = (glucose $(\mathrm{mmol} / \mathrm{l}) \times$ insulin $(\mu \mathrm{U} / \mathrm{ml})) / 22.5$ [22].

Statistical Analysis

Analyses were performed using SPSS 15.0 for Windows (SPSS, Chicago, IL, USA) and were stratified by sex. Descriptive statistics were given as median (interquartile range; IQR) or mean \pm SD (range). Mann-Whitney U-Test was used to compare means between females and males. Chisquare test was applied to analyse differences in the frequency distribution of categorical variables. Pearson's correlation was performed to demonstrate the relationship between 2 variables. To analyse an association while considering age and pubertal stage as covariates, partial correlation was adopted. To test if correlation coefficients differed from each other, significance test according to Meng et al. [23] was used [24]. Normal distribution was tested by Kolmogorov-Smirnov test. Parameters that showed no normal distribution were $\log _{10}$-transformed for correlation analysis. Bland-Altman plots for difference vs. mean for different WC measurement sites were used to determine absolute agreement between the measures [25]. To test if differences between $2 \mathrm{WC}$ measurement sites were significantly different from 0 , t-test was adopted. A p value $<0.05$ (two-sided) was considered to be statistically significant.

\section{Results}

\section{Characterisation of the Study Population}

Descriptive statistics are summarised in tables 1 and 2. When compared with males, females were shorter, had a lower FFM and higher FM. Prevalence of overweight was $11.0 \%$ for females and $13.5 \%$ for males ( $p>0.05$ ). Regarding the four different WC measurement sites, females had a lower WCR and WC4 compared to males, whereas WCM and WCC did not significantly differ between genders. However, females had lower waist-to-hip ratios than males, whereas pubertal stage, hip circumference, and cardiometabolic risk factors did not significantly differ between genders.

\section{Concordance of WC Measurement Sites}

WCs were closely related to each other (all $\mathrm{r}>0.93$; all $\mathrm{p}<$ 0.001). Nevertheless, all WCs differed from each other in their 
Table 1. Characterisation of the study population according to age, nutritional status, and pubertal stage (Mann-Whitney U-test; median (IQR) and chi-square test (\%))

\begin{tabular}{|c|c|c|}
\hline & Females $(\mathrm{n}=91)$ & Males $(n=89)$ \\
\hline \multicolumn{3}{|c|}{ Physical characteristics and body composition } \\
\hline Age, years & $13.3(10.0-16.4)$ & $13.7(10.0-16.8)$ \\
\hline Weight, kg & $46.1(33.3-60.2)$ & $52.8(37.2-67.5)$ \\
\hline Height, $\mathrm{m}$ & $1.59(1.42-1.69)$ & $1.64(1.45-1.77)^{* * *}$ \\
\hline $\mathrm{BMI}, \mathrm{kg} / \mathrm{m}^{2}$ & $19.1(16.5-21.0)$ & $19.7(17.1-21.5)$ \\
\hline BMI-SDS $^{\mathrm{a}}$ & $-0.02(-0.49-0.68)$ & $0.04(-0.53-0.84)$ \\
\hline $\mathrm{FM}, \%$ & $18.7(14.4-24.7)$ & $13.0(8.3-19.8)^{* * *}$ \\
\hline FFM, kg & $38.7(27.6-46.6)$ & $42.5(30.2-60.3)^{* *}$ \\
\hline \multicolumn{3}{|l|}{ Waist circumferences, $\mathrm{cm}$} \\
\hline WCR & $64.4(58.5-69.5)$ & $69.5(62.5-74.2)^{* * *}$ \\
\hline WC4 & $64.6(58.5-70.5)$ & $70.2(61.6-75.0)^{* *}$ \\
\hline WCM & $67.1(60.1-73.5)$ & $71.2(62.6-75.9)$ \\
\hline WCC & $71.5(63.1-80.0)$ & $74.2(64.1-80.0)$ \\
\hline Hip circumference, $\mathrm{cm}$ & $87.4(73.0-95.5)$ & $84.0(75.4-93.1)$ \\
\hline \multicolumn{3}{|l|}{ Waist to hip ratios } \\
\hline WCR/hip ratio & $0.76(0.72-0.81)$ & $0.82(0.80-0.85)^{* * *}$ \\
\hline WC4/hip ratio & $0.77(0.73-0.81)$ & $0.83(0.80-0.86)^{* * *}$ \\
\hline $\mathrm{WCM} / \mathrm{hip}$ ratio & $0.79(0.76-0.83)$ & $0.83(0.81-0.86)^{* * *}$ \\
\hline WCC/hip ratio & $0.84(0.81-0.87)$ & $0.87(0.84-0.90)^{* *}$ \\
\hline \multicolumn{3}{|l|}{ Pubertal stage, \% } \\
\hline I & 37.4 & 37.1 \\
\hline II & 5.5 & 10.1 \\
\hline III & 9.9 & 9.0 \\
\hline IV & 27.5 & 28.1 \\
\hline $\mathrm{V}$ & 19.8 & 15.7 \\
\hline
\end{tabular}

FFM = Fat free mass; FM = fat mass; SDS = standard deviation score; $\mathrm{WCC}=$ waist circumference assessed above the iliac crest; $\mathrm{WC4}=$ waist circumference assessed $4 \mathrm{~cm}$ above the umbilicus; $\mathrm{WCM}=$ waist circumference assessed midway between the lowest rib and the iliac crest; WCR = waist circumference assessed beneath the lowest rib.

$* * p<0.01 ; * * * p<0.001$ : significant difference between genders. ${ }^{a} \mathrm{n}=88$ (females) and $\mathrm{n}=83$ (males)

Table 2. Characterisation of the study population according to cardiometabolic risk factors (Mann-Whitney U-test; median (IQR))

\begin{tabular}{lcc}
\hline & Females $(\mathrm{n}=91)$ & Males $(\mathrm{n}=89)$ \\
\hline RRsys, mm Hg & $118.0(110.0-124.0)$ & $120.0(110.0-129.0)$ \\
RRdias, $\mathrm{mm} \mathrm{Hg}$ & $70.0(66.0-76.0)$ & $71.0(66.0-75.0)$ \\
Triglycerides, mg/dl & $70.0(53.8-95.5)$ & $69.0(49.0-86.0)$ \\
Cholesterol, mg/dl & $151.0(134.8-174.3)$ & $143.0(127.0-164.0)$ \\
LDL-C, $\mathrm{mg} / \mathrm{dl}$ & $76.7(61.0-91.5)$ & $69.1(57.8-88.0)$ \\
HDL-C, $\mathrm{mg} / \mathrm{dl}$ & $60.5(52.0-70.0)$ & $56.0(47.0-67.0)$ \\
Glucose, $\mathrm{mg} / \mathrm{dl}$ & $89.0(85.0-93.0)$ & $90.0(87.0-95.0)$ \\
HOMA-IR, mmol/l $\times \mu \mathrm{U} / \mathrm{ml}$ & $2.4(1.7-3.1)$ & $2.1(1.6-2.7)$ \\
&
\end{tabular}

HDL-C = High-density lipoprotein cholesterol; HOMA-IR = homeostasis model assessment of insulin resistance; LDL-C = low-density lipoprotein cholesterol; RRdias $=$ diastolic blood pressure; RRsys $=$ systolic blood pressure.
Table 3. Paired comparison of 4 waist circumference measurement sites and gender differences (mean \pm SD (range))

\begin{tabular}{lcc}
\hline & Females $(\mathrm{n}=91)$ & Males $(\mathrm{n}=89)$ \\
\hline WCM-WCR, cm & $2.8 \pm 2.8(-1.8-12.9)^{* * *}$ & $1.2 \pm 1.8(-2.1-10.2)^{* * * * \#}$ \\
WCM-WC4, cm & $2.4 \pm 2.7(-1.7-11.9)^{* * * *}$ & $0.53 \pm 1.6(-4.1-5.0)^{* * * \#}$ \\
WCM-WCC, cm & $-4.6 \pm 2.8(-14.9-0.8)^{* * *}$ & $-2.9 \pm 2.1(-10.8-1.8)^{* * * \#}$ \\
WCR-WC4, cm & $-0.41 \pm 1.6(-6.7-3.0)^{*}$ & $-0.63 \pm 1.7(-8.0-3.3)^{* *}$ \\
WCR-WCC, cm & $-7.3 \pm 4.2(-17.0-0.0)^{* * *}$ & $-4.1 \pm 3.0(-15.8-1.5)^{* * * \#}$ \\
WCC-WC4, cm & $6.9 \pm 4.1(-1.0-16.2)^{* * * *}$ & $3.4 \pm 2.8(-2.4-13.4)^{* * * * \#}$
\end{tabular}

WCC $=$ Waist circumference assessed above the iliac crest WC4 $=$ waist circumference assessed $4 \mathrm{~cm}$ above the umbilicus; $\mathrm{WCM}=$ waist circumference assessed midway between the lowest rib and the iliac crest; WCR = waist circumference assessed beneath the lowest rib.

${ }^{*} \mathrm{p}<0.05 ; * * \mathrm{p}<0.01 ; * * \mathrm{p}<0.001$ : significant different from 0 (t-test).

${ }^{\#} \mathrm{p}<0.001$ : significant difference between genders (Mann-Whitney UTest).

Table 4. Prevalence of 'overwaist' (defined as a WC $>90$ th percentile of WC reference values [17]) according to different WC measurement sites (no gender difference: chi-square test; \%)

\begin{tabular}{lll}
\hline & $\begin{array}{l}\text { Females } \\
(\mathrm{n}=91)\end{array}$ & $\begin{array}{l}\text { Males } \\
(\mathrm{n}=89)\end{array}$ \\
\hline WCR, cm & 13.2 & 15.7 \\
WC4, cm & 14.3 & 19.1 \\
WCM, cm & 18.7 & 22.5 \\
WCC, cm & 37.4 & 30.3 \\
\hline
\end{tabular}

WCC $=$ Waist circumference assessed above the iliac crest; $\mathrm{WC} 4$ = waist circumference assessed $4 \mathrm{~cm}$ above the umbilicus; $\mathrm{WCM}=$ waist circumference assessed midway between the lowest rib and the iliac crest; WCR = waist circumference assessed beneath the lowest rib.

magnitude (table 3), and systematic errors were observed for the assessment of WC (fig. 1). WCR underestimated WC compared to WCM, and the same was true for WC4 compared to WCM and WCC. On the other hand, WCC overestimated WC compared to WCM, and the same was true for WCC and WC4 compared to WCR. Except for the comparison of WCR vs. $\mathrm{WC} 4$, this effect was stronger in females compared to males (table 3). The limits of agreement (mean bias defined as the mean differences between measurement sites and $95 \%$ confidence interval $( \pm 2 \mathrm{SD}))$ were narrowest for WCR compared to WC4 (- $0.52(-3.7-2.7))$ and widest for WCR compared to WCC (-5.7 (-13.7-2.3)). Moreover, variability increased with increasing WC (fig. 1). Bias was correlated with BMI-SDS $(\mathrm{r}=0.35 ; \mathrm{p}<0.001$ (WCM vs. WCR), $\mathrm{r}=0.22 ; \mathrm{p}<0.01$ (WCM vs. WC4), $r=-0.24 ; \mathrm{p}<0.01$ (WCM vs. WCC), $\mathrm{r}=-0.22$; $\mathrm{p}<0.01$ (WCR vs. WC4), $\mathrm{r}=-0.38 ; \mathrm{p}<0.001$ (WCR vs. $\mathrm{WCC}$ ), and $\mathrm{r}=0.29 ; \mathrm{p}<0.001$ (WCC vs. WC4). However, except for the comparison of WCR vs. WC4 $(r=-0.37 ; p>0.05)$, bias was as well correlated with age $(r=0.25 ; \mathrm{p}<0.001$ (WCM vs. WCR), $\mathrm{r}=0.23 ; \mathrm{p}<0.001$ (WCM vs. WC4), $\mathrm{r}=-0.33$; 

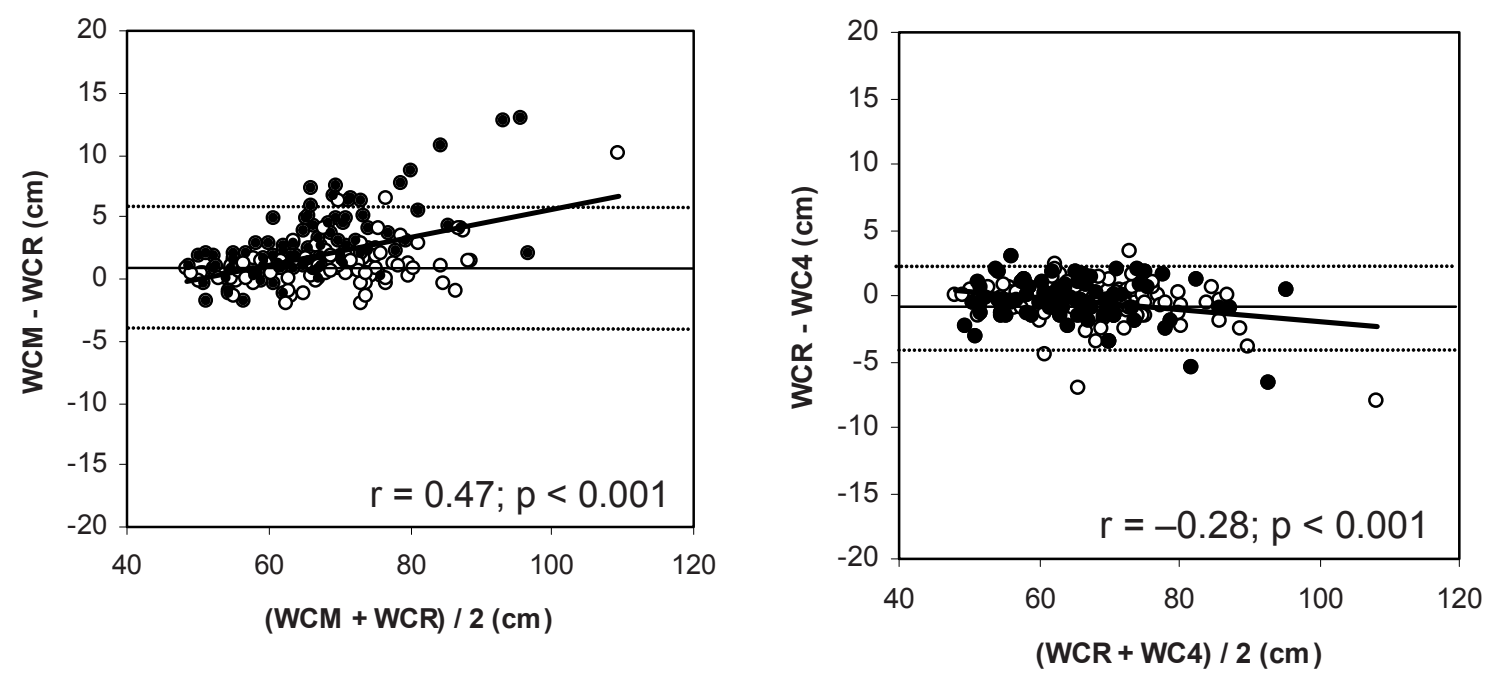

Fig. 1. Bland-Altman plots of limits of agreement in waist circumference between measurement sites. Parallel lines indicate the mean difference \pm 2 $\mathrm{SD}$; closed symbols for females, open for males. $\mathrm{WCC}=$ waist circumference assessed above the iliac crest, $\mathrm{WC4}$ = waist circumference assessed $4 \mathrm{~cm}$ above the umbilicus, WCM = waist circumference assessed midway between the lowest rib and the iliac crest, WCR = waist circumference assessed beneath the lowest rib.
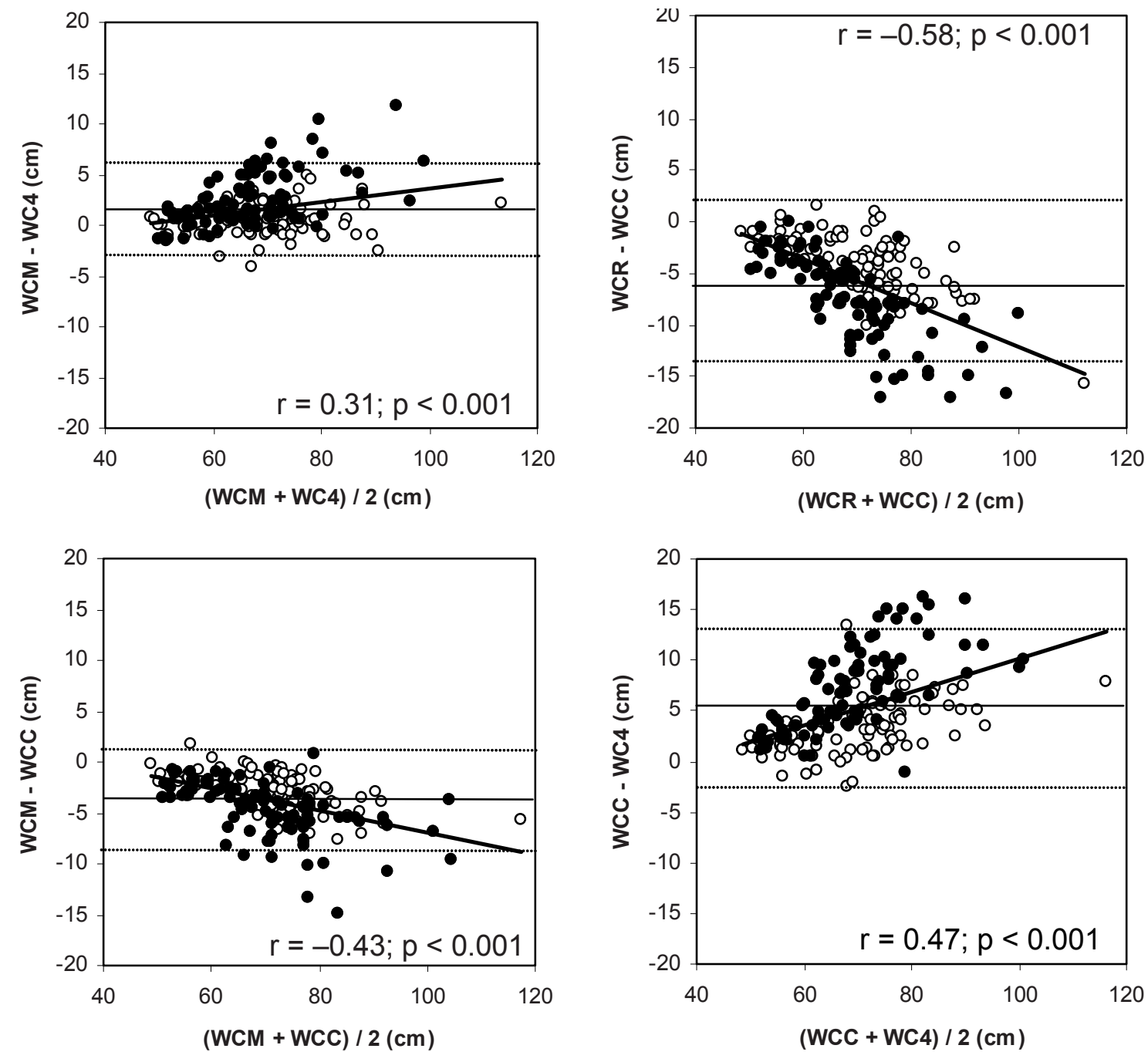

$\mathrm{p}<0.001$ (WCM vs. WCC), $\mathrm{r}=-0.37 ; \mathrm{p}<0.001$ (WCR vs. WCC), and $\mathrm{r}=0.36 ; \mathrm{p}<0.001$ (WCC vs. WC4)).

Different WC measurement sites resulted in different waistto-hip ratios (table 1), and different prevalence of 'overwaist' (table 4). In both genders, prevalence of 'overwaist' was lowest for WCR compared to WC4, WCM, as well as WCC, and no gender difference could be obtained. Since applied reference values were generated from WC measurements midway between the lowest rib and the iliac crest [17], a comparison regarding the concordance of WCR, WC4, and WCC with WCM in defining 'normal waist' and accordingly 'overwaist' was performed. $5.5 \%$ of females and $9.0 \%$ of males were discordantly 
classified into 'normal waist'/'overwaist', when comparing WCR with WCM, whereas for the comparison of WC4 vs. WCM $4.4 \%$ (females) $/ 5.6 \%$ (males) and for WCC vs. WCM $20.9 \%$ (females) $/ 7.9 \%$ (males) were discordantly classified into 'normal waist' and 'overwaist' respectively.

Relationship of WC Measurement Sites with Nutritional Status After adjusting for age and pubertal stage, all WCs were closely correlated with BMI (all $\mathrm{r}>0.86$ (females), all $\mathrm{r}>0.91$ (males); all p < 0.001) and percent FM $(\% \mathrm{FM})$ (all $\mathrm{r}>0.61$ (females), all $\mathrm{r}>0.66$ (males); all $\mathrm{p}<0.001)$. However, WCR $(\mathrm{r}=$ $0.93)$ vs. WC4 $(r=0.91)$ had a stronger correlation with BMI in males $(\mathrm{p}<0.05)$. Regarding the association between the four measured WCs and \%FM, WCC $(r=0.67)$ vs. WC4 ( $\mathrm{r}=$ $0.61)$ was stronger correlated with $\% \mathrm{FM}$ in females $(\mathrm{p}<0.05)$.

\section{Relationship of WC Measurement Sites with Cardiometabolic Risk Factors}

Correlation of cardiometabolic risk factors with WCs measured at four different sites and BMI is shown in table 5. All measures of WC were positively correlated with blood pressure, triglycerides (females), LDL-C (males), glucose levels (females), and HOMA-IR. By contrast, a negative correlation was observed for all measures of $\mathrm{WC}$ and high-density lipoprotein cholesterol (HDL-C). In females, WCC compared to WCR had a stronger correlation with triglycerides. In males, WCC compared to other WCs had a stronger correlation with LDL-C. Comparing different WC measurement sites with BMI, WCs were closer related to glucose levels (females) and HOMA-IR (both genders) as well as diastolic blood pressure (males).

\section{Discussion}

Although closely related to each other, different WC measurement sites gave different magnitudes with $\mathrm{WCR}<\mathrm{WC} 4$ $<\mathrm{WCM}<\mathrm{WCC}$ (table 1). When compared with males, these differences were more obvious for females (table 3). Moreover, systematic errors were observed for the assessment of WC between all measurement sites (fig. 1) and differences in magnitudes of WCs resulted in different waist-to-hip ratios (table 1) and prevalence of 'overwaist' (table 4). All WCs were closely correlated with BMI and \%FM. However, WCR compared to WC4 was stronger related to BMI in males and WCC vs. WC4 to \%FM in females. Regarding cardiometabolic risk factors, WCC vs. WCR had a stronger relation with triglycerides in females and WCC vs. other WCs with LDL-C in males. All other cardiometabolic risk factors were comparably associated with WCs (table 5).

\section{Concordance of WC Measurement Sites}

In line with Wang et al. [11] and Rudolf et al. [12], we could show that though highly correlated with each other, WCs dif- fered in their magnitude. Thus, WCs measured at different sites cannot be used interchangeably. This was more obvious for females compared to males (table 3 ) and was probably due to sex differences in body shape.

As shown in table 4, differences in magnitudes of WCs resulted in different prevalences of 'overwaist'. But one should keep in mind that we have applied references generated of WC measurements midway between the lowest rib and the iliac crest [17]. Reference charts for WC are available for several countries as for example Great Britain [26], China [27], and the United States [28]. These references were also generated of WC measurements midway between the lowest rib and the iliac crest. However, this could lead to bias and misinterpretation when applying these references to other WC measurement sites, since WCR as well as WC4 underestimated and WCC overestimated WC when compared with WCM (table 3). These results confirm the proposition of Wang et al. [11] that a comparison between WCs is only valid if the same measurement site is used.

Relationship of WC Measurement Sites with Nutritional Status The association between WC and BMI as well as \%FM differed according to WC measurement site. Although all WCs were highly correlated with BMI and \%FM, WCR compared to WC4 had a closer relation with BMI in males and WCC vs. WC4 with \%FM in females. This is in line with Rudolf et al. [12] who showed that three measurement sites for WC were highly correlated with BMI, although there was bias and variability between the measures. Wang et al. [11] showed that \%FM had a closer association with WCC compared to three other measurement sites. They proposed that WCC seems to be appropriate for linking VAT with a singleslice computed tomography or magnetic resonance imaging measurement, since the iliac crest is closer to L4-L5 than other measurement sites. However, a comprehensive view of different WC measurement sites regarding their association with VAT as assessed by gold standards such as magnetic resonance imaging in children and adolescents is still missing. Edwards et al. [13] used data of 15 adults with spinal cord injury and 16 able-bodied controls, where VAT was assessed by computed tomography at L4-L5 and WC was measured at three sites (WCR, WCM and WCC). Although all sites were closely correlated with VAT, WCR was the only predictor of VAT in a regression model. Whether this is also true for children and adolescents is not clear, since childhood and adolescence are periods where VAT is physiologically scarce [29] and puberty can influence the WC-VAT relationship [30]. In this context, a limitation of our study was the age range (6.1-19.9 years). Fat patterning changes rapidly during growth and sexual maturation with differences between females and males. Additionally, sex hormones differently influence subcutaneous and visceral adipose tissue [30]. Therefore, an investigation of children with a narrower age range would be preferable. 
Table 5. Relationships of waist circumferences measured at four different sites and BMI with cardiometabolic risk factors in females and males (partial correlation; adjusted for age and pubertal stage)

\begin{tabular}{|c|c|c|c|c|c|c|c|c|c|c|}
\hline & \multicolumn{5}{|c|}{ Females $(\mathrm{n}=91)$} & \multicolumn{5}{|c|}{ Males $(n=89)$} \\
\hline & $\begin{array}{l}\text { WCR, } \\
\mathrm{cm}\end{array}$ & $\begin{array}{l}\mathrm{WC4}, \\
\mathrm{cm}\end{array}$ & $\begin{array}{l}\text { WCM, } \\
\mathrm{cm}\end{array}$ & $\begin{array}{l}\text { WCC, } \\
\mathrm{cm}\end{array}$ & $\begin{array}{l}\log \text { BMI, } \\
\mathrm{kg} / \mathrm{m}^{2}\end{array}$ & $\begin{array}{l}\text { WCR, } \\
\mathrm{cm}\end{array}$ & $\begin{array}{l}\mathrm{WC4}, \\
\mathrm{cm}\end{array}$ & $\begin{array}{l}\text { WCM, } \\
\mathrm{cm}\end{array}$ & $\begin{array}{l}\text { WCC, } \\
\mathrm{cm}\end{array}$ & $\begin{array}{l}\log \text { BMI, } \\
\mathrm{kg} / \mathrm{m}^{2}\end{array}$ \\
\hline Log RRsys, mm Hg & $0.35^{* *}$ & $0.36 * *$ & $0.33 * *$ & $0.33^{* *}$ & $0.35^{* *}$ & 0.09 & 0.03 & 0.08 & 0.08 & 0.09 \\
\hline Log RRdias, mm Hg & $0.26^{*}$ & $0.30 * *$ & $0.29 * *$ & $0.26^{*}$ & $0.23 *$ & $0.23^{*}$ & $0.24 *$ & $0.24 *$ & $0.23 *$ & $0.14^{\#}$ \\
\hline Log triglycerides, $\mathrm{mg} / \mathrm{dl}$ & $0.22 *$ & $0.25^{*}$ & $0.26^{*}$ & $0.29 * * \#$ & $0.22 *$ & 0.09 & 0.10 & 0.09 & 0.09 & 0.16 \\
\hline Cholesterol, mg/dl & 0.04 & 0.04 & 0.06 & 0.07 & 0.09 & 0.12 & 0.10 & 0.13 & 0.18 & 0.11 \\
\hline LDL-C, mg/dl & 0.16 & 0.16 & 0.17 & 0.19 & 0.20 & $0.30 * *$ & $0.30 * *$ & $0.32 * *$ & $0.36 * * \#$ & $0.31 * *$ \\
\hline Log HDL-C, mg/dl & $-0.25^{*}$ & $-0.26^{*}$ & $-0.25^{*}$ & $-0.28 * *$ & -0.21 & $-0.34 * *$ & $-0.37 * * *$ & $-0.34^{* *}$ & $-0.33^{* *}$ & $-0.39 * * *$ \\
\hline $\log$ glucose, $\mathrm{mg} / \mathrm{dl}$ & $0.22 *$ & $0.22 *$ & $0.23^{*}$ & $0.23 *$ & $0.11^{\#}$ & 0.18 & 0.17 & 0.16 & 0.16 & 0.20 \\
\hline Log HOMA-IR, $\mathrm{mmol} / \mathrm{l} \times \mu \mathrm{U} / \mathrm{ml}$ & $0.36^{* *}$ & $0.38 * * *$ & $0.38^{* * * *}$ & $0.41 * * *$ & $0.23 * \#$ & $0.59 * * *$ & $0.61 * * *$ & $0.59^{* * *}$ & $0.59 * * *$ & $0.50 * * * \#$ \\
\hline
\end{tabular}

HDL-C = High-density lipoprotein cholesterol; HOMA-IR = homeostasis model assessment of insulin resistance; LDL-C = low-density lipoprotein cholesterol; RRdias = diastolic blood pressure; $\mathrm{RRsys}=$ systolic blood pressure; $\mathrm{WCC}=$ waist circumference assessed above the iliac crest; $\mathrm{WC} 4=$ waist circumference assessed $4 \mathrm{~cm}$ above the umbilicus; $\mathrm{WCM}=$ waist circumference assessed midway between the lowest rib and the iliac crest; WCR = waist circumference assessed beneath the lowest rib.

$* \mathrm{p}<0.05 ; * \mathrm{p}<0.01 ; * * * \mathrm{p}<0.001$ : correlation between WCs/BMI and cardiometabolic risk factors.

\#Significant difference between correlation coefficients (significance test according to Meng et al. [23]; Stöber and Hahn [24]):

WCC vs. WCR (log triglycerides in females; $\mathrm{p}<0.05$ ).

BMI vs. WCR, WC4, WCM, WCC (log glucose in females; all $\mathrm{p}<0.05)$.

BMI vs. WCR, WC4, WCM (all $\mathrm{p}<0.01)$ and BMI vs. WCC ( $<<0.001 ; \log$ HOMA-IR in females).

BMI vs. WCR, WC4, WCM, WCC ( $(\log R$ Rdias in males; all $\mathrm{p}<0.05)$.

WCC vs. WCR, WC4, WCM (LDL-C in males; all $\mathrm{p}<0.05$ ).

BMI vs. WCR, WC4 (all $\mathrm{p}<0.01$ ) and BMI vs. WCM and WCC (all $\mathrm{p}<0.05 ; \log H O M A-I R$ in males).

\section{Relationship of WC Measurement Sites with Cardiometabolic Risk Factors}

To our knowledge, this is the first study to investigate different measurement sites for $\mathrm{WC}$ regarding cardiometabolic risk factors in children, adolescents, and young adults (table 5). WCC vs. WCR had a stronger association with triglycerides in females. In males, WCC compared to other sites was closer related to LDL-C. However, on the basis of these results, we cannot say which method was superior. WC measurement sites need to be validated against gold standards for assessing visceral fat (such as magnet resonance imaging). One should further keep in mind technical issues in assessing WC when choosing a WC measurement site for epidemiological studies. All measurements of WC were highly reproducible (intra-observer $\mathrm{CVs}<1.5 \%)$. However, inter-observer $\mathrm{CV}$ was highest for WCC (3.1\%). The assessment of WCC might be difficult, since the waist shape above the iliac crest decreases more than the waist shape in other regions of the trunk; it might be problematic stabilising the measurement tape on a sharply curved skin surface [11].However, technical issues need also be considered when assessing other WCs. Regarding WCR, the mea- surement site must be standardised to immediately below the end of the lowest rib [11]. The measurement of WC4 in children/adolescents with a wide age range may not be comparable, since the landmark at ' $4 \mathrm{~cm}$ above the umbilicus' results in different positions. WCM measurements require the landmarking of two sites (WCR and WCC); a misplacing of either landmark has significant effects on the data [11].

In conclusion, in children, adolescents, and young adults, variability was seen between different measures of WC so that WCs measured at different sites cannot be used interchangeably. This was more obvious in females than in males. As a consequence, there is a need for an internationally accepted WC measurement site. At present, a concordance of WC measurement sites should be assured when applying WC references to define 'overwaist'.

\section{Acknowledgement}

This work was supported by the Bundesministerium für Bildung und Forschung (BMBF Network Kiel - Dietary Fat and Metabolism project 6.1.2).

\section{References}

1 IOTF: EU childhood obesity 'out of control'. IOTF childhood obesity report, May 2004

2 Cali AM, Caprio S: Prediabetes and type 2 diabetes in youth: an emerging epidemic disease? Curr Opin Endocrinol Diabetes Obes 2008;15:123-127.
3 Bibbins-Domingo K, Coxson P, Pletcher MJ, Lightwood J, Goldman L: Adolescent overweight and future adult coronary heart disease. N Engl J Med 2007:357:2371-2379.
4 Lee S, Bacha F, Arslanian SA: Waist circumference, blood pressure, and lipid components of the metabolic syndrome. J Pediatr 2006;149:809-816.

5 Li Y, Yang X, Zhai F, Piao J, Zhao W, Zhang J, Ma G: Childhood obesity and its health consequence in China. Obes Rev 2008;9:82-86. 
6 Maffeis C, Corciulo N, Livieri C, Rabbone I, Trifirò G, Falorni A, Guerraggio L, Peverelli P, Cuccarolo G, Bergamaschi G, Di Pietro M, Grezzani A: Waist circumference as a predictor of cardiovascular and metabolic risk factors in obese girls. Eur J Clin Nutr 2003;57:566-572.

7 Savva SC, Tornaritis M, Savva ME, Kourides Y, Panagi A, Silikiotou N, Georgiou C, Kafatos A: Waist circumference and waist-to-height ratio are better predictors of cardiovascular disease risk factors in children than body mass index. Int $\mathrm{J}$ Obes Relat Metab Disord 2000;24:1453-1458.

8 Hirschler V, Aranda C, de Luján Calcagno M, Maccalini G, Jadzinsky M: Can waist circumference identify children with metabolic syndrome? Arch Pediatr Adolesc Med 2005;159:740-744.

9 Janssen I, Heymsfield SB, Allison DB, Kotler DP, Ross R: Body mass index and waist circumference independently contribute to the prediction of nonabdominal, abdominal subcutaneous, and visceral fat. Am J Clin Nutr 2002;75:683-688.

10 Onat A, Avcı GȘ, Barlan MM, Uyarel H, Uzunlar B, Sansoy V: Measures of abdominal obesity assessed for visceral adiposity and relation to coronary risk. Int J Obes 2004;28:1018-1025.

11 Wang J, Thornton JC, Bari S, Williamson B, Gallagher D, Heymsfield SB, Horlick M, Kotler D, Laferrère B, Mayer L, Pi-Sunyer FX, Pierson RN $\mathrm{Jr}$ : Comparison of waist circumference measured at 4 sites. Am J Clin Nutr 2003;77:379-384.

12 Rudolf MCJ, Walker J, Cole TJ: What is the best way to measure waist circumference? Int J Pediatr Obes 2007;2:58-61.

13 Edwards LA, Bugaresti JM, Buchholz AC: Visceral adipose tissue and the ratio of visceral to subcutaneous adipose tissue are greater in adults with than in those without spinal cord injury, despite matching waist circumferences. Am J Clin Nutr 2008;87 600-607.
14 Danielzik S, Czerwinski-Mast M, Langnäse K, Dilba B, Müller MJ: Parental overweight, socioeconomic status and high birth weight are the major determinants of overweight and obesity in 5-7y-old children: baseline data of the Kiel Obesity Prevention Study. Int J Obes Relat Disord 2004;28: 1494-1502.

15 Kromeyer-Hauschild K, Wabitsch M, Kunze D, Geller F, Geiß HC, Hesse V, Von Hippel A, Jaeger U, Johnsen D, Korte W, Menner K, Müller G, Müller MJ, Niemann-Pilatus A, Remer T, Schaefer F, Wittchen HU, Zabransky S, Zellner K, Ziegler A, Hebebrand J: Perzentile für den Body-mass-Index für das Kindes- und Jugendalter unter Heranziehung verschiedener deutscher Stichproben. Monatsschr Kinderheilkd 2001;149:807-818.

16 WHO: Physical Status: The Use and Interpretation of Anthropometry. Technical Report series 1995.

17 Fredriks AM, van Buuren S, Fekkes M, VerlooveVanhorick SP, Wit JM: Are age references for waist circumference, hip circumference and waist-hipratio in Dutch children useful in clinical practice? Eur J Pediatr 2005;164:216-222.

18 Bosy-Westphal A, Danielzik S, Becker C, Geisler C, Onur S, Korth O, Bührens F, Müller MJ: Need for optimal body composition data analysis using AirDisplacement Plethysmography in children and adolescents. J Nutr 2005;135:2257-2262.

19 Tanner JM: Growth at Adolescence. Oxford, Blackwell Scientific Publication, 1962.

20 Duke PM, Litt IF, Gross RT: Adolescents' self-assessment of sexual maturation. Pediatrics 1980;66: 918-920.

21 Friedewald WT, Levy RI, Fredrickson DS: Estimation of the concentration of low-density lipoprotein cholesterol in plasma, without use of the preparative ultracentrifuge. Clin Chem 1972;18:499-502.
22 Matthews DR, Hosker JP, Rudenski AS, Naylor BA, Treacher DF, Turner RC: Homeostasis model assessment: insulin resistance and beta-cell function from fasting plasma glucose and insulin concentrations in man. Diabetologia 1985;28:412-419.

23 Meng XL, Rosenthal R, Rubin DB: Comparing correlated correlation coefficients. Psychol Bull 1992;111:172-175.

24 Stöber J, Hahn A: Signifikanztest für zwei korrelierte Korrelationen. 1999. userpage.fu-berlin.de/ ahahn/sigcorr.html.

25 Bland JM, Altman DG: Statistical methods for assessing agreement between two methods of clinical measurement. Lancet 1986;i:301-310.

26 McCarthy HD, Jarrett KV, Crawley HF: The development of waist circumference percentiles in British children aged 5.0-16.9y. Eur J Clin Nutr 2001;55:902-907.

27 Sung RYT, Yu CCW, Choi KC, McManus A, Li AMC, Xu SLY, Chan D, Lo AFC, Chan JCN, Fok TF: Waist circumference and body mass index in Chinese children: cutoff values for predicting cardiovascular risk factors. Int J Obes 2007;31:550-558.

28 Freedman DS, Serdula MK, Srinivasan SR, Berenson GS: Relation of circumferences and skinfold thicknesses to lipid and insulin concentrations in children and adolescents: the Bogalusa Heart Study. Am J Clin Nutr 1999;69:308-317.

29 Goran MI, Kaskoun M, Shuman WP: Intra-abdominal adipose tissue in young children. Int $\mathrm{J}$ Obes Relat Metab Disord 1995;19:297-283.

30 Brambilla P, Bedogni G, Moreno LA, Goran MI, Gutin B, Fox KR, Peters DM, Barbeau P, De Simone M, Pietrobelli A: Crossvalidation of anthropometry against magnetic resonance imaging for the assessment of visceral and subcutaneous adipose tissue in children. Int J Obes 2006;30:23-30. 